\title{
8 \\ Plant genetic resources of Papua New Guinea some thoughts on intellectual property rights
}

\section{RN Kambuou}

Over the last 20 years, there has been an increasing interest and enthusiasm for biodiversity prospecting and the development of natural products throughout the world. The exploration of biodiversity for commercially valuable genetic resources has the potential to encourage conservation and to provide economic benefits to developing countries and their local communities. However, despite the interest and rapidly increasing number of biodiversity prospectors, there are no clear national policies or legislation in place to govern and regulate biodiversity prospecting in Papua New Guinea.

This chapter discusses forms of law that might provide protection for intellectual property rights in plant genetic resources. It also discusses international undertakings and agreements that support individual countries' efforts to establish these kinds of protection.

\section{Plant genetic resources in Papua New Guinea}

It is estimated that Papua New Guinea contains more than 5 per cent of the world's total biodiversity, in less than 1 per cent of its land area. The country is also one of the world centres of diversification of traditional root and tuber crops, leafy vegetables, fruits and nuts, cooking bananas, underutilised food crops, sugarcane, medicinal plants, ornamental trees and timber trees. These are a rich and valuable resource that must be appropriately utilised and conserved for future generations. 
While this diversity is still largely intact, genetic erosion is taking place at an alarming rate in some places, mainly caused by urbanisation and increased lumbering, mining and agriculture activities. Mining and logging operations are changing the lifestyle of villages to that of a cash economy, and the indigenous diversity of crops is gradually being lost. The underutilised food crops and medicinal plant resources are disappearing as the older generations who are the users of these germplasms die, while the younger generations move to urban centres and mining sites. Valuable indigenous knowledge about the use of these plant varieties is vanishing with the older generation.

Papua New Guinea has approximately 38 million hectares of forest, spreading over 60 per cent of the country's land mass, of which more than 97 per cent is customarily owned by the indigenous inhabitants (Swartzendruber 1993). These forest habitats contain the country's valuable forest tree resources. Indigenous timber tree species include the Araucaria spp., Agathis spp., Eucalyptus spp., Acasia spp. and some exotic species such as Tectona grandis, Gmelina arborea and Ochroma lagopus.

There are more than 600 medicinal plants reportedly used in Papua New Guinea (Holdsworth 1977). Almost all these plants grow wild in their natural habitats and are collected by villagers whenever medical needs arise. The forest habitats of the country, particularly the rainforest areas, are rich storehouses for nearly 3,000 exotic orchid species, as many as 15,000 species of wild flowers and many species of ornamental shrubs, ferns, palms, mammals, birds, reptiles, insects and other organisms (Beehler 1992).

The production of staple food crops remains the most important agricultural activity for 85 per cent of the rural population. Subsistence farmers and local communities in Papua New Guinea follow complex farming systems. The main crops in the farming system are sweet potatoes, taro, yams, cassava, bananas and traditional leafy vegetables.

\section{Germplasm collections}

National ex situ collections of germplasm are held for major food crop species, fruits and nut tree species and some underutilised food crop species and ornamental plants-the latter being maintained in the National Botanical Gardens. Well over 7,000 accessions of 42 crop plant species were initially collected and are maintained in ex situ field collections. A recent report (Kambuou 1995) on freld collections reported that 1,474 accessions of 41 plant species are being maintained. 
Unfortunately, the rest of the collected germplasm has been lost because of funding constraints.

\section{Bioprospecting}

Advances in technology have enabled quick and inexpensive screening of wild products for potential agricultural, pharmaceutical and industrial development. Indigenous knowledge of bush medicine can lead researchers to discover potentially useful and naturally occurring medicinal compounds, and Papua New Guinea's isolated and culturally highly variable communities could provide valuable genetic information for the field of medicine. It is no surprise, therefore, that scientific and industrial demand for access to Papua New Guinea's genetic resources is increasing. Given the current trend, the value of Papua New Guinea's genetic resources for medicinal and industrial applications is likely to increase in the future. The time is now ripe for Papua New Guinea and the other island countries in the South Pacific region to take stock of these invaluable resources and start formulating policies to govern sustainable biodiversity prospecting.

\section{Export of germplasm from Papua New Guinea}

The germplasm of the 'noble cane' (Sacharum officinarum) of New Guinea is a good example of a valuable germplasm that was taken out of its centre of origin to help develop the sugarcane industry elsewhere. The earliest expedition to collect sugarcane was undertaken in 1875 . Since then several collecting trips have occurred. Some of these genetic materials are now held in the world collections run by the United States Department of Agriculture, Agricultural Research Service (USDA/ARS), while the fate of others, in particular those collected during earlier expeditions, are unknown.

Other crop resources that have been collected and taken out of the country include bananas (Musa spp.), various roots and tuber crops (Ipomoea batatas, Dioscorea spp., Colocasia esculenta), aibika (Abelmoschus manihot) and coconut (Cocos nucifera). Apart from the conservation and safe keeping of this germplasm in the regional or international genebanks, the level of utilisation remains unknown.

The National Botanical Gardens has encountered the illegal exportation of orchids in the past, and this will pose a major problem in the future if the law is not enforced. Some unconfirmed reports suggest 
that numerous orchids have been illegally exported on timber ships. To avoid the illegal exportation of such genetic resources, existing laws need to be strengthened. Long-term planning is needed to develop national policies on intellectual property rights and other rights, including those provided for in the International Undertaking on Plant Genetic Resources and the Convention on Biological Diversity.

\section{National laws and policies for protection of plant genetic resources}

Intellectual property law systems operating in many countries have conventionally provided five different types of intellectual property rights that might be used to protect plant genetic resources-patents, plant breeder rights, trademarks, copyright and trade secrets. The two mechanisms most suited to plant genetic resources are patents and plant breeder rights. More recently, there has been international debate about the development of a new form of protection for plant genetic resources, farmers' rights.

The Papua New Guinea legal system does not presently provide for any of these forms of protection, nor is there any national policy on intellectual property rights for plant genetic resources. However, there are other laws that relate to the protection of plants and animals, and general government policy on sustainable agricultural development and the preservation of natural resources and the environment, including the regulation of the export of native flora and fauna.

\section{Policy on agricultural resources}

Government policy on the development of agriculture reflects the following objectives

- facilitating the assessment of the environmental and social impact of agricultural development projects

- promoting sustainable and environmentally sound agricultural practices

- conservation, assessment and the effective use of genetic diversity of plant and animal species to help maintain and improve the agricultural environment

- research on the development of methods, including biological control methods, that will reduce the impact of agricultural pests, diseases and weeds 
- development of an institutional capacity to undertake regulation, monitoring and testing of agrochemicals and agricultural outputs

- maximum involvement of local people in all aspects of agricultural development and implementation of agricultural projects.

\section{Protection of indigenous flora}

There are several laws that provide protection for the flora of Papua New Guinea and prohibit the export of these resources. These include

- Fauna (Protection and Control) Act

- International Trade (Fauna and Flora) Act

- National Parks Act

- Forestry Act

- Quarantine Act

- Customs (Prohibited Export) and (Prohibited Import) Regulations. The Department of Environment and Conservation and the National Agriculture Quarantine and Inspection Authority are responsible for enforcing these laws through licensing systems that require wildlife export permits, Convention on International Trade in Endangered Species certificates and phytosanitary certificates for the export of plant material. These systems are intended to protect plant genetic resources for a variety of policy reasons. For example, Convention on International Trade in Endangered Species certificates are required as part of an international legal framework that protects endangered species threatened by international trade.

Although this legal framework is in place, the enforcement of these Acts and regulations is unsatisfactorily or ineffectively monitored. This has resulted in many valuable genetic materials leaving Papua New Guinea without proper permit procedures being followed.

\section{International undertakings and agreements}

\section{Convention on Biological Diversity}

Perhaps the most significant international instrument in terms of plant genetic resources is the Convention on Biological Diversity. A total of 157 nations (including Papua New Guinea) have signed the Convention and 65 countries ratified it at that time. The Convention on Biological Diversity is a framework agreement which is legally binding and came into force on 29 December 1993, having been signed by Papua New Guinea in 1992. It provides an international legal justification and a 
framework for the country to establish sovereign rights over its genetic resources.

The objectives of the Convention on Biological Diversity are the conservation of biological diversity and the sustainable use of its components. It promotes fair and equitable sharing of the benefits arising from the utilisation of genetic resources, including appropriate access to genetic resources, and the appropriate transfer of relevant technologies, taking into account all rights over those resources and technologies (Article 1). Article 1 effectively authorises nations to establish regimes to regulate access to their genetic resources.

The Convention on Biological Diversity also deals with the rights of indigenous communities. It directs parties to 'respect, preserve, and maintain knowledge, innovations, and practices of indigenous and local communities, embodying traditional lifestyles that are relevant for the conservation and sustainable use of biological diversity' (Article 8).

The most significant achievement of the Convention on Biological Diversity is the establishment of the concept of national sovereignty over resources. The concept of states' sovereign rights over natural resources has replaced the common heritage principle, and access to a country's genetic resources must be on mutually agreed terms and with the prior informed consent of the state owning the resources. Prior informed consent is an important aspect of any access agreement and any country declining to require prior informed consent risks uncontrolled and free access to its resources. However, the sovereign rights concept does not apply to the resources that are already in the international repositories, only to those materials located within a country's borders at the time the Convention came into force.

\section{International Undertaking on Plant Genetic Resources}

The purpose of the International Undertaking on Plant Genetic Resources is to ensure that germplasm of economic or social interest, particularly for agriculture, will be explored, preserved, evaluated and made available for plant breeding and scientific research purposes. The principle aim of this undertaking is to redefine the common heritage of mankind and plant genetic resources, including those created by modern techniques.

A number of amendments have been made to the Undertaking since 1983. In 1989, Resolution 5/89 was adopted. It redefined the concept of farmers' rights as rights arising from the past, present and future contributions of farmers in conserving, improving and making available 
plant genetic resources, particularly those in the centres of origin of diversity. The Undertaking also recognises the sovereign rights of countries over their plant genetic resources. The Undertaking gives the Commission on Plant Genetic Resources of the Food and Agriculture Organisation responsibility for monitoring developments with respect to intellectual property rights legislation, and assessing their implications for the Undertaking.

\section{Code of Conduct for Plant Germplasm Collection and Transfer}

The Code of Conduct for Plant Germplasm Collection and Transfer provides a practical approach to recognition of the sovereign rights of individual countries over the plant genetic resources in their territories. Based on this principle, conservation and continued availability of plant genetic resources is a common concern of mankind. In executing these rights, access to plant genetic resources should not be unduly restricted. The Code further contemplates the right of the permit issuing authority to grant or refuse a permit, and that collectors and sponsors should take into account the relevant national laws.

\section{Trade-Related Aspects of Intellectual Property Rights}

\section{Agreement}

The Trade-Related Aspects of Intellectual Property Rights Agreement is the most comprehensive international instrument on intellectual property ever negotiated and adopted. Under this Agreement, signatory countries are required to enact a variety of laws relating to intellectual property rights. These include laws protecting plant varieties, either by patents or by an effective sui generis system (such as plant breeder rights).

The Agreement increases protection and incentives for breeders and the biotechnology industry. Products or processes must be capable of industrial application before they can be eligible for patent protection. It can be argued that the Agreement supports and protects those activities that are multinational and trade-related in nature. Countries that are members of the International Union for the Protection of New Varieties of Plants comply with the Trade-Related Aspects of Intellectual Property Rights Agreement requirement of an effective sui generis system, and with advancement in technology, other countries will join and 
adopt the legislation of the International Union for the Protection of New Varieties of Plants.

The Trade-Related Aspects of Intellectual Property Rights Agreement can also be said to be in conflict with the Convention on Biological Diversity because it effectively provides incentives for those promoting uniformity in plant varieties, as opposed to incentives for in situ conservation of a diversity of genetic resources.

Countries that are bound by the Trade-Related Aspects of Intellectual Property Rights Agreement may decide to protect plant varieties either by means of patents or by a sui generis system. The possibility exists for combining both the patents and plant breeder right protection systems. The protection of plant varieties on the basis of patents may have important implications for access to genetic materials for the development of new materials and the on-farm use of seeds. For this reason, it is likely that many developing countries may consider the use of a sui generis system based on the concept of plant breeder rights.

\section{Intellectual property rights and local communities}

None of the international undertakings or agreements described above gives effective rights to local communities that are the rightful custodians of the rich genetic resources diversity in developing countries. It is important that these international agreements and undertakings recognise, realise and respect the rights of local communities who are the producers, innovators and custodians of the majority of genetic diversity. At present, these undertakings are narrow in scope, and effectively only recognise innovation and production when it takes place under the control of transnational corporations, and in conformity with the individualised context of the Western legal system.

Under the Convention on Biological Diversity, the rights of biodiversity are the sovereign rights of the nation states (Article 3). These rights can only exist if they are built on the rights of communities that have conserved and protected biodiversity within national territories for many decades. The people of Papua New Guinea lead a communal life in close relationship with nature and the environment that surrounds them. It is of utmost importance that the government stands behind the people in protecting biodiversity, especially the rich diversity in plant genetic resources. 


\section{Definitions of knowledge and creativity}

Intellectual property rights are intended to provide recognition and reward for intellectual creativity or to secure ownership over products of the human mind. However, knowledge and creativity have been so narrowly defined in the context of intellectual property rights that the creativity of nature and traditional knowledge systems have been ignored.

The intellectual property rights system that is being advocated under the Trade-Related Aspects of Intellectual Property Rights Agreement contains little scope for recognising innovation by millions of farmers and communities in developing countries, where biological diversity is concentrated and from where most knowledge of use has evolved. The governments of developing countries are being pressured to adopt immediately an intellectual property right system for plant genetic resources that serves only the narrow interests of commercial plant breeders in industrial countries. In developing new sui generis systems, developing country governments should focus on the rights of the farmers and local communities who have been the original innovators in the utilisation of plant genetic diversity.

\section{Limitations of patents and plant breeder rights}

Patents are the strongest form of intellectual property right protection. They give the inventor of a product or process exclusive monopoly rights over its commercialisation. The product or process must be new, useful and an improvement from the original art to qualify for a patent. When applied to plant genetic resources (as is the case in some countries) patent law does not allow farmers to reuse the seeds that they have obtained, and does not allow protected varieties to be used for further breeding, unless it is for research purposes with no commercial interest. The patent system varies from one country to another, because it is determined by each country's national legislation. These laws should be made flexible to cater for the needs of resource-poor farmers and farming communities in developing countries, who may not have the purchasing powers to pay for the seeds.

Plant breeder rights protect varieties which are new, distinct, uniform and stable. Breeder rights exclude non-authorised persons from using and multiplying propagating materials of protected varieties, but 
generally allow farmers to reuse, for the purpose of planting further crops, the seeds that they have obtained. Breeder rights, under a breeders' exemption, allow protected varieties to be used for further breeding, without the authorisation of the inventor of the variety. This is seen as an advantage in the field of plant improvement, as it is possible to freely exchange valuable germplasm.

The contributions made by the farmers and local communities in Papua New Guinea and in other developing countries in the conservation, selection and regeneration of plant genetic resources have been substantial, and it has been widely agreed that there should be some form of recognition for their invaluable efforts.

\section{Farmers' rights}

The concept of farmers' rights was originally proposed in 1983 as an amendment to the International Undertaking on Plant Genetic Resources of the Food and Agriculture Organisation. It is intended to provide a measure of counterbalance to formal intellectual property rights by providing a system of intellectual property rights tailored to the needs of farmers who have, over many generations, bred food crop varieties for their own use. Farmers' rights are based on the recognition of the intellectual creativity and innovative capacity of farmers. They are not assigned to specific varieties, types of plants or farmers. Rather, their purpose is to encourage farmers and farming communities to nurture, conserve, utilise and improve plant genetic resources (Food and Agriculture Organisation 1993). In the development of a new sui generis system for Papua New Guinea, focus should be placed on the rights of farmers and local communities.

\section{Conclusion}

The purpose of the discussions in this volume is to provide an informative basis for the citizens of Papua New Guinea to discuss how to respond to issues about use of, and access to, genetic resources. The Convention on Biological Diversity has effectively challenged nations to think creatively about national sovereignty, conservation and the sustainable use of plant genetic resources; about fair and equitable sharing of the benefits arising from the use of these resources; and about 
how Papua New Guinea might best protect its rich diversity in plant, animal and marine genetic resources.

Hopefully the suggestions and ideas set out here will continue to stimulate discussion at higher government levels. Most importantly, this discussion should lead to action, in particular to develop relevant and appropriate legislation on intellectual property rights to protect the interests, knowledge and techniques of the farmers and local communities who have helped to give us access to the wealth of biodiversity we enjoy today. 